\title{
The Effect of Team-Based Learning on Conventional Pathology Education to Improve Students' Mastery of Pathology
}

\author{
Bin $\mathrm{Du}^{1} \&$ Xuesong Yang ${ }^{2}$ \\ ${ }^{1}$ Department of Pathology, School of Medicine, Jinan University, Guangzhou 510632, China \\ ${ }^{2}$ Division of Histology and Embryology, Key Laboratory for Regenerative Medicine of the Ministry of Education, \\ School of Medicine, Jinan University, Guangzhou 510632, China
}

Correspondence: Xuesong Yang, Division of Histology and Embryology, Key Laboratory for Regenerative Medicine of the Ministry of Education, School of Medicine, Jinan University, Guangzhou 510632, China

Received: March 30, 2017

Accepted: April 18, 2017

Online Published: April 28, 2017

doi:10.5430/ijhe.v6n3p12

URL: https://doi.org/10.5430/ijhe.v6n3p12

\begin{abstract}
In recent decades, traditional pathology education methodologies have been noticeably affected by new teaching approaches, including problem-based learning (PBL) and team-based learning (TBL). However, lack of outcome-based studies has hindered the extensive application of the TBL approach in the teaching of pathology in Chinese medical schools. In this study, a pilot TBL format on four topics in pathology was implemented in one session with medical students at Jinan University Medical School and the previous sessions of medical students were able to function as controls. The final exam scores of TBL participants were significantly higher than the scores for non-participants, indicating that the students demonstrated better academic performance at the end of the TBL class. In addition, the follow-up questionnaires revealed that the majority of the TBL participants spent more time studying and were actively and enthusiastically involved in TBL activities. The new teaching format also inspired teachers' desire to lead discussions and administer quizzes instead of repeating rote didactics. Overall, this pilot study reveals that a combination of the TBL approach and traditional pathology theory can improve pathology education.
\end{abstract}

Keywords: Pathology education, TBL approach, Traditional teaching, Thrombosis, Medical students

\section{Introduction}

A branch of medical science, pathology is chiefly the study of the causes, origins and nature of disease. In other words, pathology addresses the mechanisms underlying injury to cells and tissues and how the body responds to injury by examining tissues, organs, bodily fluids and autopsies. Obviously, pathology is an indispensible course for a medical student because pathology creates a bridge between basic science and clinical medicine (Just PA, Verkarre V, Mansuet-Lupo A, Rabant M, Daniliuc C, Radenen B, Harent M, Cassanelli L, Cherel É, Javaux H, Tesniere A, Terris B, \& Badoual C., 2016)( Iversen, O.H., 1997). The primary goals of teaching pathology to medical undergraduates are to develop scientific thinking, describe the variety of diseases, and develop a knowledge of the functional and morphological changes in disease so that the medical students can understand clinical symptoms and pathological diagnoses.

Over the past decades, the reformation of medical education has dramatically affected the traditionally didactic teaching methods for medical undergraduates on a world scale (wan JY, Nyhof-Young J, Catton P, \& Giuliani ME.,2015)( Knap, J.P., 2012) (Deckers, P.J.,2000). Therefore, more and more medical schools all over the world have adopted new teaching approaches, such as problem-based learning (PBL), interdisciplinary integration of pre-clinical and clinical practices and team-based learning (TBL) ( Fincham, A.G. \& C.F. Shuler.,2001)( Trappler, B.,2006)( Thompson BM, Schneider VF, Haidet P, Levine RE, McMahon KK, Perkowski LC, \& Richards BF., 2007). TBL method was originally developed by Michaelsen for business education (Michaelson LK, Fink LD, \& Knight A., 1997). In recent years, TBL has been a well-defined instructional strategy, which is widely used in different medical courses of medical education, such as anatomy, physiology and histology (Vasan NS, DeFouw DO, \& Holland BK.,2008)(Goldberg HR, \& Dintzis R.,2007). Compared to passively learning in traditional lectures, TBL can provide students with the opportunity to solve clinical problems using theoretical knowledge in class(Goldberg HR, \& Dintzis R.,2007). It is worth noting that the TBL application in a pathology residency program truly promotes the apprentices' teamwork and learning ability(Brandler TC, Laser J, Williamson AK, Louie J, \& Esposito MJ.,2014). 
Hrynchak P et al. demonstrated that TBL helped students to improve their ability to work within teams, solve challenging problems and develop critical thinking skills (Hrynchak P, \& Batty H.,2012). Although TBL is based on small group interaction as PBL, TBL approach allows a single teacher to simultaneously manage many small groups in a large class (Vasan NS, DeFouw DO, \& Holland BK.,2008) (Hrynchak P, \& Batty H.,2012). Considering the large number of students in many Chinese medical schools, TBL is suitable for teaching a large cohort of students at the same time. To date, however, TBL has not been widely introduced into undergraduate pathology courses in China.

At Jinan University Medical School, pathology is typically taken by medical undergraduates during the second year of their enrollment in the five-year program. The pathology curriculum includes 118 total teaching hours for medical students majoring in Clinical Medicine and for students enrolled in the Bachelor of Medicine, Bachelor of Surgery (MBBS) program. The pathology curriculum is evenly divided into theoretical lectures and practical laboratory sessions. In China, student knowledge and competencies are generally assessed by examinations prepared by teaching staff. Many new teaching formats, such as integrated courses and PBL, have been widely adopted in the various basic sciences and clinical medical courses at Jinan University Medical School despite considerable resistance from both teachers and students(Sanqiang Pan, Xin Cheng, Yanghai Zhou, Ke Li, \& Xuesong Yang., 2017) (Lu, Xiaoye, Cheng, Xin, Li, Ke, Lee, Kenneth Ka Ho, \& Yang, Xuesong., 2016) (Zhang MY, Cheng X, Xu AD, Luo LP, Yang X.,2015). Here, we combine the pathology knowledge taught in traditional lectures with a TBL class in which a portion of the pathology practice laboratories was replaced. The medical students were requested to utilize their knowledge from the pathology lectures to analyze a case. In TBL, the students mastered the characteristics of pathologic morphology and, more importantly, were trained in how to analyze and address a case in a clinical setting rather than simply remembering pathological features in practice, which also enhances students' enthusiasm for learning pathology.

\section{Materials and Methods}

\subsection{Student Participants}

The pathology curriculum is normally offered to medical students during their second year of medical school at Jinan University Medical School, Guangzhou, China. The TBL approach to pathology study was implemented in 2013 to a total of 160 medical students enrolled in the 2012 medical program. The pilot project was pre-approved by the Teaching Affairs Unit of Jinan University in the spring of 2013. Non-participating students were the medical students enrolled in the 2012 medical program (no TBL approach was implemented then) who were used as controls to evaluate the efficacy of the TBL classroom approach to learning. The conventional curriculum consists of theoretical sessions twice a week (90-minute lectures delivered in the classroom) and weekly laboratory practical sessions (90-minute sessions for viewing pathological specimens and histology slides). In place of four of the practical laboratory sessions, four 2-hour TBL sessions were conducted on different days. The teachers were trained prior to the TBL sessions by reading books and articles and attending a seminar on TBL. Topics included thrombosis, chronic obstructive pulmonary disease, coronary heart disease and cirrhosis resulting from chronic viral hepatitis. Thus, the TBL classroom was implemented according to the schedule of previous practical laboratory sessions without altering the normal teaching hours.

To avoid diversity between TBL participants and non-participants, we checked the demographic details of all participants in the TBL classroom study. The total number of TBL students was 160, and the students were enrolled in the 2013 medical program at Jinan University Medical School. The medical students enrolled in 2012 were used as controls (TBL non-participants) because no TBL class was implemented at that time. The average anatomy scores of the non-participants and TBL participants were $69.56 \pm 17.30$ and $70.68 \pm 18.69$, respectively $(\mathrm{p}=0.685$, Cohen's $\mathrm{d}=0.228$ ). The average GPAs of the non-participants and the TBL classroom students were $3.28 \pm 0.42$ and 3.36 \pm 0.58 , respectively ( $\mathrm{p}=0.268$, Cohen's $\mathrm{d}=0.368$ ), suggesting that there were not considerable dissimilarities in the learning ability of non-participants and TBL class participants at the outset of the study. Significantly, the TBL class was arranged according to the normal schedule of the pathology class so that no extra teaching hours were required for the TBL class. The total in-class contact hours between teachers and students were identical for non-participants and TBL participants. The principal difference between the two teaching formats was that the pre-class assignments were assigned prior to the class for the TBL students, causing those students to be more actively involved in the teaching activity compared with traditional lectures in which the students were asked to remember the morphological characteristics of some diseases. Although no pre-testing is really implemented prior to TBL, there are considerable differences on the students' learning ability between the TBL-involved and non-TBL-involved groups. 


\subsection{Study Protocol}

Students had access to Blackboard (Blackboard Inc., Washington, DC) for networking and access to online virtual microscopy, which allowed the participants to view pathological specimens and histology slides outside of dedicated classroom time. The general arrangement of the TBL classroom for pathology education is presented in Figure 1. A thrombosis specimen as an example and the corresponding histological slides are illustrated in Figure 2. Video recordings and relevant learning materials were also uploaded onto Blackboard in addition to an online bank of pathology items. All of the learning resources uploaded onto Blackboard were available to the students studying pathology during the academic year, regardless of their participation in the TBL program.

The TBL model utilized currently is illustrated in Figure 1, which represents the activities that occurred during a typical class period. The TBL classroom protocol included a pre-class task (preparation) assigned one week prior to class, consisting of viewing study material and reading the in-class design plan. Every pre-class task (preparation) focused on specific teaching objectives such as thrombosis and was designed and adapted to what students had learned in their traditional theory class, an important connection. During the TBL class, three types of quizzes were administered, personal, team and overall quizzes, typically covering the relevant material learned during that session. Quiz question formats varied and included multiple-choice and open-ended questions. Personal quizzes typically consist of 10-20 multiple-choice questions. Immediately after the personal quizzes, the students need to discuss with their teams to reach consensus answers. Team quizzes force their team members to engage in and refine their team process to maximize the score of the team. A key feature of the team quizzes is immediate feedback to the answers. It is facilitated by using special Immediate Feedback-Assessment Technique cards (Figure 3), in which the correct answer is shown when the coating is scratched off, and the points will be lost for each incorrect attempt. Overall quizzes are usually the cases or other real-world scenarios that require team members to make a decision through the application of course concepts. At the end of the TBL class time, the tutors and students each developed a summary, and the participants answered the questionnaires for the TBL class.

\subsection{Study Design}

Medical students' test scores were employed as the assessment index. At Jinan University Medical School, pathology test scores are composed of separate theoretical and practical components. For each portion of the exam, a one hundred percentage-point system was used. The score for the theoretical section of the examination was converted into $70 \%$ of the final overall score, and the rest of the score was derived from the practical microscopy portion. The examination included multiple-choice questions (MCQ), short-answer questions, fill-in-the-blank items, and essay questions. All TBL-participant and non-TBL-participant students involved in this study were tested using identical examinations at the end of the semester. The papers were graded by the same teachers, thus allowing for direct comparison of the learning outcomes as measured and determined by examination performance. The TBL classroom approach was only utilized for the thrombosis, chronic obstructive pulmonary disease, coronary heart disease and cirrhosis curriculum, which are subcomponents of the entire pathology curriculum. The final examinations of both groups of students were independently collected by two members of the teaching staff. A questionnaire was designed utilizing Sojump, an online questionnaire provider, to obtain feedback on the TBL classroom experience from participating students. The survey consisted of 20 items, and 7 of the items used a five-point Likert scale wherein students were requested to rank their responses: strongly disagree, disagree, neutral, agree, and strongly agree. The percentages based on the numbers of students who selected a score of 4 and above were calculated to quantify the feedback from TBL classroom students. The remaining four items were free text answers. All respondents completed the online survey. Their responses were captured anonymously in Sojump, which de-identified the aggregated information. The results generated by the surveys were collected and reviewed. However, the test scores of these Clinical Medicine TBL classroom participants were not incorporated into this study because the teaching syllabus and examinations were different for this case.

\subsection{The TBL Class was Implemented Following the Corresponding Theory Lecture}

We did not change anything about the theory courses in pathology. Pathology theory courses for TBL participants and non-TBL participants were taught with identical content. We believe that it is crucial for students to master theory knowledge before participating in the TBL class. Therefore, as always, we earnestly taught the content of each chapter in pathology. For the pathology of thrombosis, for example, the teacher addressed the following fundamental concepts: 1) the conditions for thrombosis contain infection, intravenous drug use and malignancy; 2) the colors of thrombus are red, white or a mix of those colors; 3 ) the embolus could occur in the form of thrombus, fat or air; and 4) the embolism paths are composed of vein and artery pathways. If there is a vein pathway, the thrombosis could occur in the pulmonary artery, and could be in the brain, kidney or spleen if there is an artery pathway for 
thrombosis.

Previously, we simply asked students to view the pathological specimens and histological sections of a thrombus during the practical section, which was implemented for non-TBL participant students (control). We introduced one case and explained it in detail in the lesson of thrombosis. This case is involved in a healthy young male sailor who suffered a fracture at sea. The doctor on the ship provided some general medical treatment including bandaging the wound and applying a plaster cast for 3 months. When the wounded sailor returned to China, he is basically able to participate in normal activities, and then he died suddenly a few months later. The subsequent pathological specimens and histological sections from the autopsy are presented in Figure 1. The diagnosis was an embolism in the pulmonary trunk. In the TBL class, we organized students to discuss the case based on their pathological knowledge from the theory lecture: 1) Where do the thrombi and adipose embolus come from? 2) How does an embolism circulate? 3) How does thrombosis occur? 4) What is the pathological basis of sudden death induced by embolism? 5) How can one avoid a thrombosis? Based on the knowledge about thrombosis taught in the theory lecture, the TBL-participant students could very well understand why thrombosis of the pulmonary trunk was diagnosed in this case, although the students had not yet mastered the pathological characteristics included in traditional pathological practice.

\subsection{Data Analysis}

All statistical and graphical analyses were conducted using the SPSS statistical package, version 17.0 (IBM Corp., Armonk, NY). An independent sample t-test (2-tailed) was conducted to assess the demographic characteristics of all participants involved in the study and the examination scores of TBL classroom participants and non-participants. The data obtained from the questionnaires were analyzed using the Cronbach's alpha test to determine the internal consistency of the responses. Kendall's tau B test was used to assess the validity and reliability of each item listed in the questionnaire. Following the construct validity approach reported by Broomfield et al. (Broomfield D., \& Bligh J., 1998), factor analysis with varimax rotation was used to determine the principal factors that may account for the variance in the overall sample. The average Likert scores for each item were presented as the mean \pm SD.

\subsection{Ethical Considerations}

This study was approved by the Research Ethics Committee at Jinan University and conducted according to the Helsinki Declaration.

\section{Results}

\subsection{The TBL Class Based on Theory Lecture Improved the Effectiveness of Students'Learning of Pathology}

The effect of the TBL approach to learning pathology was assessed by analyzing the scores on the final pathology exam achieved by TBL class participants $(n=160)$ and non-participants $(n=120$, control) (Figure 4).The results indicated that the average test scores for TBL participants and non-participants were 70.42 \pm 0.91 and $63.36 \pm 1.23$, respectively. Overall, the results indicated that the TBL approach based on theory lectures could boost learning outcomes among medical students.

\subsection{The TBL Class Based on Theory Lecture Stimulated the Students'Enthusiasm for Studying Pathology}

The students' enthusiasm for studying pathology was indicated by their attendance in class and the participants' questionnaires (Table 1). First, compared with attendance in pathology practice in 2012 (control), the TBL attendance in 2013 increased significantly without any supervisor encouragement, indicating that the TBL format was more attractive to students.

Second, the questionnaire regarding students' responses to the TBL class from TBL participants also indicated that the majority of participants agreed. "This course improved my interest in learning pathology" and "I was motivated to study hard during this course". TBL was why "I put more time into this course than I did previously," according to a majority of the interviewees (Table 1). Many of the participant students reported that the TBL format helped them learn and understand pathology better. TBL students could also consolidate their learning by solving problems in class. "I enjoyed this learning experience" and "This course promoted my ability to collaborate with other students" were sentiments echoed by the majority of participants. Of course, we must mention that several students strongly preferred the traditional lecture/practical teaching method because those students believed that the TBL teaching format was inappropriate (Table 1). Most comments suggested that the TBL format indeed promoted students' enthusiasm for learning pathology for the majority of medical students. 
Table 1. Summary of Responses from the Students $(n=160)$

\begin{tabular}{llllll}
\hline Items & $\mathbf{1}$ & $\mathbf{2}$ & $\mathbf{3}$ & $\mathbf{4}$ & $\mathbf{5}$ \\
\hline This course improve my interesting on learning pathology & 42 & 71 & 23 & 15 & 9 \\
This course help me understanding theoretical courses & 30 & 67 & 39 & 14 & 10 \\
I was motivated to study hard during this course & 43 & 73 & 22 & 10 & 12 \\
I put more time into this course than I did previously & 64 & 70 & 12 & 9 & 5 \\
I preferred this format for improving my ability to analyze cases & 37 & 68 & 26 & 17 & 12 \\
This course promoted my ability to collaborate with other students & 43 & 79 & 21 & 15 & 2 \\
I enjoyed this learning experience & 51 & 73 & 18 & 15 & 3 \\
\hline
\end{tabular}

Likert scale: 1 , strongly agree; 2 , agree; 3 , neutral; 4, disagree; 5 , strongly disagree

\section{Discussion}

Clearly, the single format of traditional didactic lecturing in medical education is currently being challenged. This movement away from simple lectures is in fact impelled by trends in several factors of medical education, including the increases in the scope of medical knowledge, the use of new pedagogical technologies, less time allocated to basic medical science, and exponential increases in the number of medical students, particularly in China in the last decade. Under such conditions, an urgent question our medical educators must address is how to deliver medical knowledge to medical students more effectively and efficiently (Nematollahi, S., P.A. St John, \& W.J., 2015). Another important issue is the many complaints expressed in recent years regarding young Chinese medical graduates lacking practical skills despite possessing advanced doctoral degrees(Wu L, Wang Y, Peng X, Song M, Guo X, Nelson H, \& Wang W., 2014). Although the reasons arise due to multiple factors that medical students have spent less time practicing a variety of medical-related skills is not among those reasons. The traditional medical education system has not yet adapted to the current needs of the modern medical profession. Specifically, training modern medical practitioners using conventional didactic formats cannot fulfill the new requirements of interdisciplinary, pre-clinical and clinical practices in China. Poorly trained doctors negatively compound medical errors and endanger patients' safety(Rubin, P. and D. \& Franchi-Christopher., 2002). Accordingly, the Chinese Medical Education Association has recently launched an integral component of healthcare reform to improve medical education. Certainly, medical students will benefit greatly from the series of medical education reforms when those students become doctors and are facing patients. Therefore, various pilot curricula and integrations of medical education reform have appeared on the Jinan University campus, where students have previously been taught solely by traditional didactic lectures. However, we must remember that traditional didactic lectures do have their place in efficiently delivering knowledge and have for many years. Instead of giving up the traditional teaching format completely, we combine lectures' advantages with a new teaching format, TBL, in this study.

Using the clinical attachment "thrombosis", we described the implementation of the TBL class in detail in our pathology teaching. The pathology test scores were significantly higher among participants than non-participants, indicating that the meaningful student learning outcomes were significantly enhanced by the TBL class approach, which is consistent with another published study (Davidson, L.K., 2001). Furthermore, the feedback regarding the overall impressions of TBL implementation on the study of pathology was obtained from a questionnaire answered by TBL participants. The survey revealed that most TBL participants spent more time studying pathology than would have been normally spent in traditional pathology practice, implying that TBL participants' increased learning activities contributed to their better learning outcomes as measured by their test scores. Previous studies reported that the level of student engagement in a discipline is significantly related to learning outcomes (Pike GR, Smart JC, \& Ethington CA., 2012). This study clearly indicates that the TBL approach increased student engagement in the study of pathology, which can partially account for participants' better performance in learning pathology. The greater engagement of TBL participants in studying pathology may also be reflected in better attendance in the TBL class than for previous pathology practices. The perceived effects of the TBL teaching format on knowledge acquisition have also been confirmed by Haidet et al. (Haidet, P., K. Kubitz, \& W.T. McCormack, 2014). In fact, both better attendance in class and more time spent studying demonstrated that the TBL teaching format enhanced the students' enthusiasm for learning. This enthusiasm arose from students' spontaneous learning activities, not from being pushed by teachers or examinations. The most remarkable outcome was that the students' spontaneous study not only enhanced their performance on tests but also improved their analytical skills, which are specifically required when these students become real doctors in the future. 
In this study, the tutor who organized the TBL class was a male associate pathology professor with 10 years of experience teaching pathology and with clinical experience; two teaching assistants were responsible for answering students' questions, etc., during the TBL. TBL in-class hours strictly adhered to the university teaching syllabus on pathology. The teachers' pedagogical abilities were favorably evaluated based on students' annual anonymous feedback. Certainly, the teachers of the TBL class spent more time preparing clinical cases and attachments for the new curriculum than for traditional pathological practice, at least for the first several times that the TBL pathology was implemented at Jinan University. An advantage is that TBL requires far fewer tutors than PBL does, which is crucial for the majority of Chinese medical schools because the ratio of teachers to students is too low. Instructors are inspired by the challenge of new teaching methodologies because they realize that their role has evolved from simply delivering knowledge to coaching, mentoring, and guiding students during interactive classroom activities( Park, S.E. \& T.H. Howell., 2015). Although the average score of final exam on TBL group was higher than non-TBL, we found that the gap between the highest score and the lowest score was increased in TBL group. It suggests that TBL made good student better but weak student worse. Several studies also reflected students' the lower levels of satisfaction with TBL than other teaching methods such as small group or lecture (Willett LR, Rosevear GC, \& Kim S., 2011)(Haidet P, Morgan RO, O'Malley K, Moran BJ, \& Richards BF., 2004)(Hunt DP, Haidet P, Coverdale JH, \& Richards B., 2003). Therefore, there is no doubt that further study is required about how to overcome the defects of TBL.

Overall, this study indicates that medical students at Jinan University Medical School may benefit from a combination of the TBL approach and traditional pathology lectures. The pathology final exam demonstrated that the TBL combination helped TBL participants to higher achievement. The subsequent questionnaires revealed that the majority of TBL students actively participated in case discussions and analysis with great enthusiasm. In addition, the instructors themselves were inspired by the new teaching format. The TBL approach following a pathology lecture can serve as a potentially exciting new approach to teaching pathology. Certainly, further investigation is required to fully evaluate the format before its experience is extended to other disciplines at Jinan University.

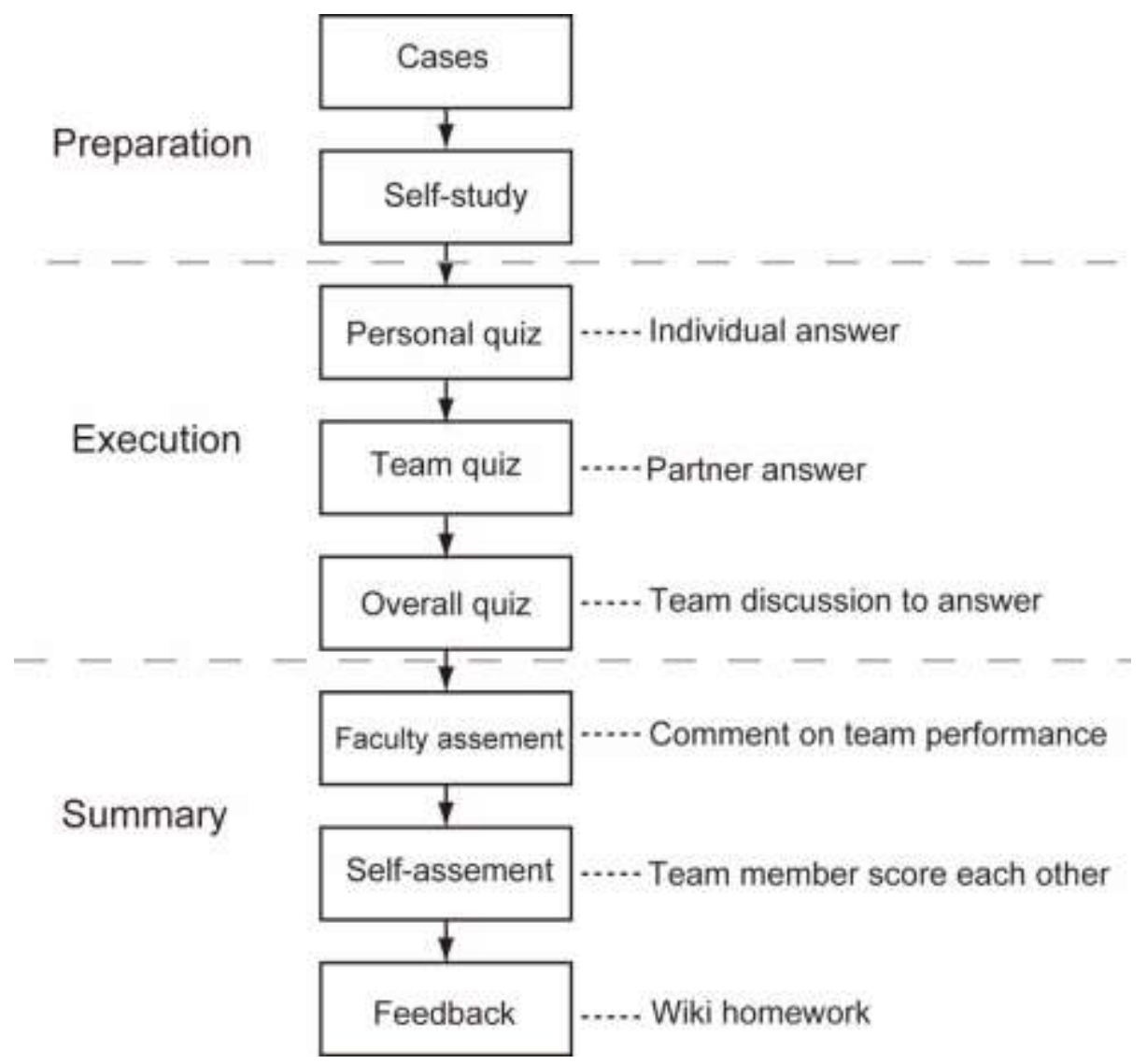

Figure 1. Schematic diagram demonstrating the TBL structure and teaching model

The contents include the students' tasks before class (preparation) and how to implement the TBL and quizzes in the TBL class (execution and summary). 
A

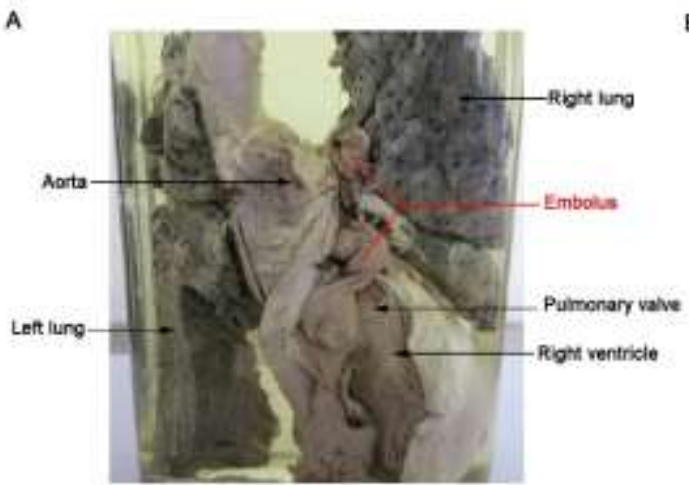

c

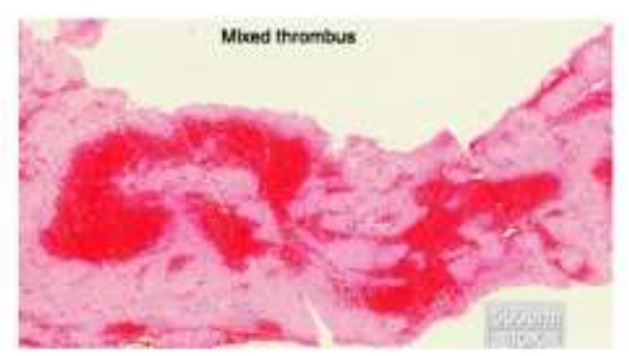

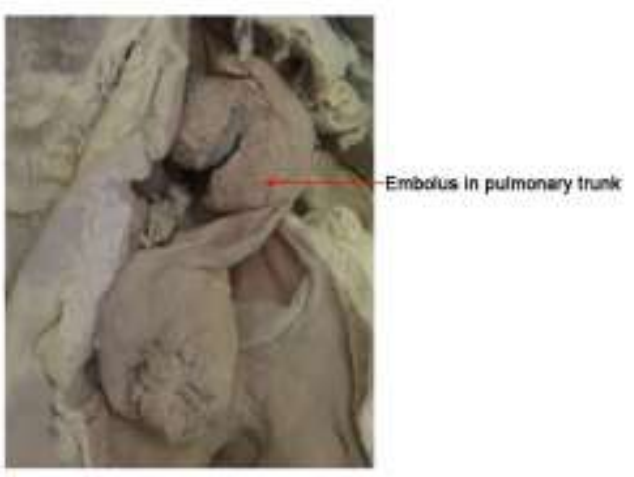

D

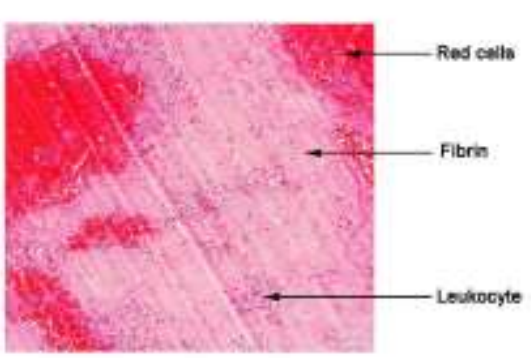

Figure 2. The pathological specimens and histological sections of thrombosis in the pulmonic trunk

A: The pathological specimens of thrombosis in pulmonic trunks. B: The high magnification image showing the site of thrombosis. C: The histological sections of thrombosis in pulmonic trunks. D: The high magnification image taken from the sites indicated by the dotted square in B.

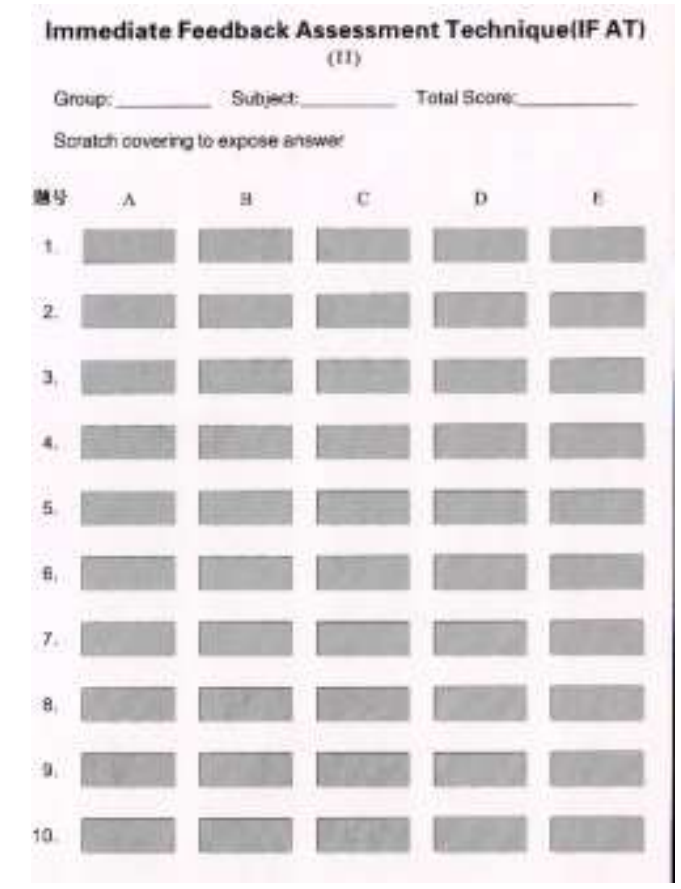

Figure 3. A sample of scratch tickets for the self-assessment quiz questions with immediate feedback assessment technique

This is a sample of the self-assessment quiz regarding viewing a histological section, which was taken from a branch of the right main pulmonary artery in an autopsy, displaying a band of fibrous connective tissue that extends across the lumen. 


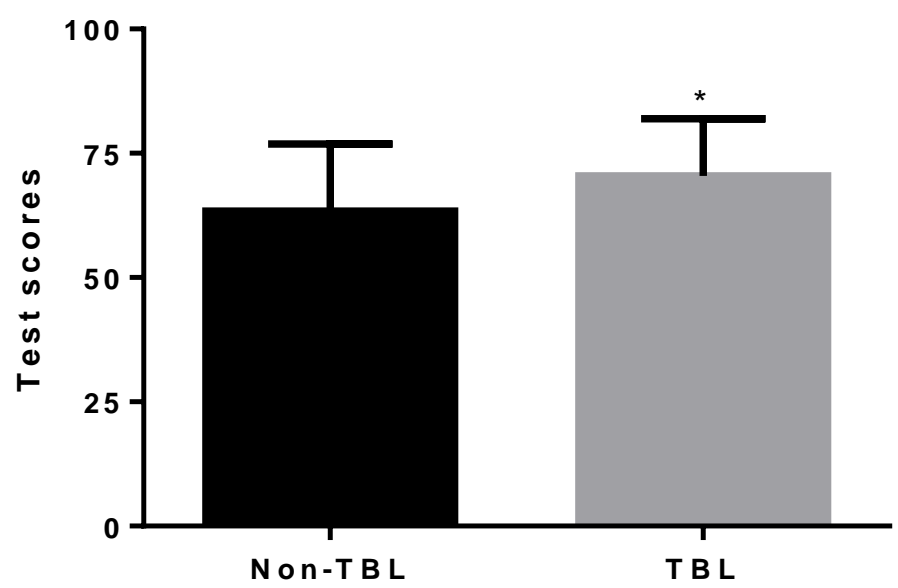

Figure 4. The comparison of students' scores on the final pathology exam between TBL participants and non-participants

The bar chart shows a comparison of students' scores on the final pathology exam between TBL non-participants (traditional didactic teaching approach) $(\mathrm{n}=160)$ and the TBL participants (TBL classroom teaching approach) $(n=120)$.

\section{Competing Interests}

The authors declare that there are no conflicts of interest.

\section{Acknowledgements}

This study is supported by the grants from 2016 Guangdong Province Project of discipline construction and pedagogical reform of high education and $16^{\text {th }}$ Research Projects of Pedagogical Reform at Jinan University (JG2014026).

\section{References}

Brandler TC, Laser J, Williamson AK, Louie J, \& Esposito MJ. (2014). Team-based learning in a pathology residency training program. Am J Clin Pathol, 142(1), 23-8. https://doi.org/10.1309/AJCPB8T1DZKCMWUT

Broomfield D, \& Bligh J. (1998). An evaluation of the short 'form course' experience questionnaire with medical students. Med Educ, 32, 367-369. https://doi.org/10.1046/j.1365-2923.1998.00232.x

Davidson, L.K. (2011). A 3-year experience implementing blended TBL: active instructional methods can shift student attitudes to learning. Med Teach, 33(9), 750-3. https://doi.org/10.3109/0142159X.2011.558948

Deckers, P.J. (2000). Health care reform and undergraduate medical education: implications for surgeons. Arch Surg, 135(4), 399-408. https://doi.org/10.1001/archsurg.135.4.399

Fincham, A.G. \& C.F. Shuler (2001). The changing face of dental education: the impact of PBL. J Dent Educ, 65(5), 406-21. http://jdentaled.org/content/65/5/406.long

Goldberg HR, \& Dintzis R. (2007). The positive impact of team-based virtual microscopy on student learning in physiology and histology. Adv Physiol Educ, 31(3), 261-5. https://doi.org/10.1152/advan.00125.2006

Haidet P, Morgan RO, O'Malley K, Moran BJ, \& Richards BF. (2004). A controlled trial of active versus passive learning strategies in a large group setting. Adv Health Sci Educ Theory Pract., 9(1), 15-27. https://doi.org/10.1023/B:AHSE.0000012213.62043.45

Haidet, P., K. Kubitz, \& W.T. McCormack. (2014). Analysis of the Team-Based Learning Literature: TBL Comes of $\begin{array}{lllll}\text { Age. } J & \text { Excell } & \text { Coll } & \text { 303-333. }\end{array}$ https://www.ncbi.nlm.nih.gov/pmc/articles/PMC4643940/pdf/nihms-730983.pdf

Hrynchak P, \& Batty H. (2012). The educational theory basis of team-based learning. Med Teach, 34(10), 796-801. https://doi.org/10.3109/0142159X.2012.687120

Hunt DP, Haidet P, Coverdale JH, \& Richards B. (2003). The effect of using team learning in an evidence-based 
medicine course for medical students. Teach Learn Med, 15(2), 131-9. https://doi.org/10.1207/S15328015TLM1502_11

Iversen, O.H., (1997). The teaching of pathology in undergraduate education programs in medicine in Europe. Pathol Res Pract, 1997. 193(4), 241-56. https://doi.org/10.1016/S0344-0338(97)80001-5

Just PA, Verkarre V, Mansuet-Lupo A, Rabant M, Daniliuc C, Radenen B, Harent M, Cassanelli L, Cherel É, Javaux H, Tesniere A, Terris B, \& Badoual C., (2016). Innovations in medical undergraduate pathology education: The Paris Descartes medicine faculty experience. Ann Pathol, 36(4), 252-7. https://doi.org/10.1016/j.annpat.2016.04.006

Knap, J.P. (2012). Reform of epidemiology undergraduate education programme for Polish medical students--the changes threatening essentials of education in medical reasoning. Przegl Epidemiol, 66(4), 559-65. http://www.przeglepidemiol.pzh.gov.pl/pobierz-artykul?id=1535

Lu, Xiaoye, Cheng, Xin, Li, Ke, Lee, Kenneth Ka Ho, \& Yang, Xuesong. (2016). Integration of Histology Lectures and Practical Teaching in China. International Journal of Higher Education, 5, 157-164. https://doi.org/10.5430/ijhe.v5n4p157

Michaelson LK, Fink LD, \& Knight A. (1997). Designing effective group activities: lessons for classroom teaching and faculty development. In: DeZure D, ed. To Improve the Academic Resources for Faculty, Instructional and Organizational Development. Stillwater, OK: New Forums Press, 373-9 p.

Nematollahi, S., P.A. St John, \& W.J. Adamas-Rappaport. (2015). Lessons learned with a flipped classroom. Med Educ, 49(11), 1143. https://doi.org/10.1111/medu.12845

Park, S.E. \& T.H. Howell. (2015). Implementation of a flipped classroom educational model in a predoctoral dental course. J Dent Educ, 79(5), 563-70. http://www.jdentaled.org/content/79/5/563.full.pdf+html

Pike GR, Smart JC, \& Ethington CA. (2012). The mediating effects of student engagement on the relationships between academic disciplines and learning outcomes: An extension of Holland's theory. Res High Educ, 53, 550-575. https://doi.org/10.1007/s11162-011-9239-y

Rubin, P. \& D. Franchi-Christopher. (2002). New edition of Tomorrow's Doctors. Med Teach, 24(4), 368-9. https://doi.org/10.1080/0142159021000000816

Sanqiang Pan, Xin Cheng, Yanghai Zhou, Ke Li, \& Xuesong Yang. (2017). Seeking the Optimal Time for Integrated Curriculum in Jinan University School of Medicine. International Journal of Higher Education, 6, 25-33. https://doi.org/10.5430/ijhe.v6n1p25

Thompson BM, Schneider VF, Haidet P, Levine RE, McMahon KK, Perkowski LC, \& Richards BF. (2007). Team-based learning at ten medical schools: two years later. Med Educ., 41(3), 250-7. https://doi.org/10.1111/j.1365-2929.2006.02684.x

Trappler, B. (2006). Integrated problem-based learning in the neuroscience curriculum--the SUNY Downstate experience. BMC Med Educ, 6, 47. https://doi.org/10.1186/1472-6920-6-47

Vasan NS, DeFouw DO, \& Holland BK. (2008). Modified use of team-based learning for effective delivery of medical gross anatomy and embryology. Anat Sci Educ, 1(1), 3-9. https://doi.org/10.1002/ase.5 http://dx.doi.org/10.1002/ase.5

wan JY, Nyhof-Young J, Catton P, \& Giuliani ME. (2015). Mapping the future: towards oncology curriculum reform in undergraduate medical education at a Canadian medical school. Int J Radiat Oncol Biol Phys, 91(3), 669-77. https://doi.org/10.1016/j.ijrobp.2014.11.017

Willett LR, Rosevear GC, \& Kim S. (2011). A trial of team-based versus small-group learning for second-year medical students: does the size of the small group make a difference? Teach Learn Med, 23(1), 28-30. https://doi.org/10.1080/10401334.2011.536756

Wu L, Wang Y, Peng X, Song M, Guo X, Nelson H, \& Wang W. (2014). Development of a medical academic degree system in China. Med Educ Online, 15(19), 23141. https://doi.org/10.3402/meo.v19.23141 https://www.ncbi.nlm.nih.gov/pmc/articles/PMC3895259/

Zhang MY, Cheng X, Xu AD, Luo LP, \& Yang X. (2015). Clinical simulation training improves the clinical performance of Chinese medical students. Med Educ Online, 20(1), 28796. https://doi.org/10.5430/ijhe.v5n4p157 http://dx.doi.org/10.5430/ijhe.v5n4p157 